\begin{tabular}{ccc|} 
ISSN = 1980-993X - doi:10.4136/1980-993X \\
www.agro.unitau.br/ambi-agua \\
E-mail: ambi-agua@agro.unitau.br \\
Tel.: (12) 3625-4116
\end{tabular}

\title{
Validação do método para a determinação do ácido 3 - indolacético em água de rios por cromatografia líquida de alta eficiência
}

(doi:10.4136/ambi-agua.75)

\author{
Sérgio Marcos Sanches; Renata Martins²; Paulo Jorge Marques Cordeiro² ${ }^{2}$ Luiz \\ Augusto Artemonte Vaz ${ }^{3}$; Eny Maria Vieira ${ }^{2}$ \\ ${ }^{1}$ Escola de Enfermagem de Ribeirão Preto/USP \\ E-mail: sesanches@hotmail.com \\ ${ }^{2}$ Instituto de Química de São Carlos/USP \\ E-mail: rennata_m@yahoo.com.br; \{cordeiro,eny\}@iqsc.usp.br \\ ${ }^{3}$ Empresa Agrolatino, Matão \\ E-mail: sellyap@hotmail.com
}

\section{RESUMO}

O ácido 3 - indolacético (AIA) é um importante fitormônio natural encontrado em plantas em baixas concentrações. O AIA está envolvido na regulação dos processos de crescimento e desenvolvimento de plantas. Neste estudo foi desenvolvido e validado o método analítico para a determinação e quantificação do ácido 3 - indolacético em amostras de água. A cromatografia líquida de alta eficiência com detector de arranjo de diodos foi empregada como técnica analítica para a determinação do ácido 3 - indolacético. Os parâmetros selecionados para a validação do método foram: limite de detecção e quantificação, linearidade, curva analítica, precisão, sensibilidade e ensaios de recuperação. A curva analítica foi construída com cinco pontos, empregando-se solução padrão. O método

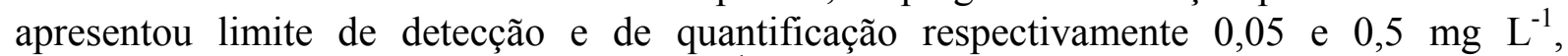
linearidade no intervalo de 0,5 a $10 \mathrm{mg} \mathrm{L}^{-1}$, o coeficiente de correlação foi superior a 0,99 . Com base nesses resultados, conclui-se que o método é eficiente e pode ser empregado em análise para o monitoramento do ácido 3 - indolacético presente em águas naturais.

Palavras-chave: água; validação; ácido 3 - indolacético.

\section{Validation of the method for determining the 3 - indolacetic acid in water from rivers by high performance liquid chromatography}

\section{ABSTRACT}

The 3 - indolyacetic acid is an important natural phytohormone in plants in low concentrations. The 3 - indolyacetic acid is involved in the regulation of many processes of growth and plants development. This study developed and validated an analytical method to quantify 3- indolyacetic acid using the Hight-Performance Liquid Chromatography with DAD detector. The following parameters were chosen: detection and quantification limits, linearity, calibration curve, precision, sensibility and assays of recovery. The calibration curve was obtained with five points based on standard solution. The method presented detection and quantification limits of 0.05 and $0.5 \mathrm{mg} \mathrm{L}^{-1}$, respectively. It showed linearity in the interval of 0.5 to $10 \mu \mathrm{g} \mathrm{L}^{-1}$ and correlation coefficients higher than 0.99 . These results allow the conclusion that the method can be considered efficient and that it could be used to monitor 3 indolyacetic acid in natural water.

Keywords: water; validation; 3 - indolyacetic acid. 


\section{INTRODUÇÃO}

Os vegetais, assim como os animais, têm grande parte de seu metabolismo controlado por hormônios. O desenvolvimento e crescimento das plantas são afetados pela luz, gravidade, temperatura, fotoperíodo, por meio da influência dos hormônios vegetais (Rolcik et al., 2005). Os fitormônios correspondem a uma série de compostos que agem em muitos fenômenos vegetais tais como, crescimento, floração, divisão celular, amadurecimento de frutos, dormência de gemas. Os principais fitormônios são: auxinas, giberelinas, ácido abscísico e etileno (Rolcik et al., 2005). Desses, os mais importantes são as auxinas e neste caso o ácido 3 - indolacético (AIA).

O AIA é uma substância de crescimento pertencente ao grupo das auxinas. Ele é encontrado em plantas e microrganismos em baixas concentrações, e foi à primeira auxina isolada responsável por numerosos processos biológicos em vegetais. É responsável pela regulação de processos de crescimento e desenvolvimento de plantas como, dominância apical, crescimento de brotos, divisão e elongação celular (Wurst et al., 1984).

Existem várias rotas para a biossíntese do AIA, sendo o aminoácido triptofano o seu provável precursor. Suspeita-se da existência de uma outra via independente do triptofano para a biossíntese desse hormônio vegetal (Arteca, 1995). Apesar de ambas as vias coexistirem nas plantas, a importância relativa de cada uma para o conteúdo de AIA nos tecidos vegetais, ainda não foi esclarecida. Esse hormônio é sintetizado principalmente no meristema apical em folhas jovens e é transportado em sentido polarizado (do ápice para a base), a partir do meristema apical até as extremidades das raízes (Arteca, 1995; Wachowicz e Carvalho, 2002).

As auxinas podem ser encontradas naturalmente nos vegetais sob a forma livre ou conjugada. O AIA, na forma livre, é a forma biologicamente ativa do hormônio, mas a grande maioria é encontrada na forma conjugada. As plantas regulam o nível de AIA livre através de uma complexa rede de vias que além da síntese incluem o transporte, a degradação, a conjugação com aminoácidos, as proteínas, a glicose e o inositol e a hidrólise destes conjugados. A conjugação do AIA é um processo que ocorre em praticamente todos os vegetais superiores e os conjugados de AIA formam-se rapidamente quando a homeostase do hormônio é perturbada como, por exemplo, na aplicação externa de AIA no tecido vegetal (Artega, 1995). Quando conjugado com glicosídeos, o AIA serve basicamente como reserva e quando a conjugação ocorre com aminoácidos ou proteínas é utilizado para desintoxicação (Wachowicz e Carvalho, 2002).

O AIA pode ser degradado na planta por meio da foto-oxidação e pela oxidação enzimática realizada pelo sistema AIA-oxidase (Alvarenga e Carvalho, 1983) pois a ruptura da molécula do AIA garante o seu nível, portanto a nova síntese depende desse processo para regular a taxa hormonal na planta. Inicialmente, o AIA era utilizado somente para o enraizamento de plantas, posteriormente, para promover a floração em amendoim, evitar a abscisão e promover a partenocarpia de frutos como, maçã, abóbora e berinjela (Castro et al., 1993).

O principal objetivo deste estudo foi o desenvolvimento e validação do método analítico para a determinação do ácido 3 - indolacético em amostras de água. Não existe legislação (Brasil, 2004) que mencione o AIA como sendo uma substância que deve ter seu limite máximo na água. 


\section{MATERIAL E MÉTODOS}

\subsection{Preparo da solução padrão do ácido 3- indolacético}

Preparou-se uma solução padrão do ácido 3 - indolacético de concentração de $100 \mathrm{mg} \mathrm{L}{ }^{-}$ 1 em metanol.

\subsection{Seleção do comprimento de onda utilizado em HPLC - UV}

Foi obtido um espectro de absorção do padrão ácido 3 - indolacético que compreendeu uma varredura de 200 a $800 \mathrm{~nm}$. Utilizou-se um Espectrofotômetro de UV/Visível da marca Hitachi, modelo U3501.

\subsection{Condições cromatográficas ideais para a determinação do ácido 3 - indolacético em água de rios}

As determinações analíticas do ácido 3 - indolacético foram feitas na Central de Análises Químicas do Instituto de Química de São Carlos-USP empregando um cromatógrafo com detector de arranjo de diodos, da marca SHIMADZU CBM-10A. Foi utilizada uma coluna de fase reversa $\left(\mathrm{C}_{18}\right)$, da marca Zorbax ODS, de $15 \mathrm{~cm}$ de comprimento, diâmetro interno de 4,6 $\mathrm{mm}$ e o tamanho de partícula de $5 \mu \mathrm{m}$. As condições cromatográficas para a análise do AIA foram: detector de arranjo de diodos; fluxo de $1,0 \mathrm{~mL} \min ^{-1}$; volume injetado de $20,0 \mu \mathrm{L}$; comprimento de onda a $280 \mathrm{~nm}$; temperatura ambiente, fase móvel metanol/TFA $0,05 \%$ $(40: 60 \mathrm{v} / \mathrm{v})$, método isocrático.

\subsection{Preparo da curva analítica e linearidade}

Após determinar as condições cromatográficas ideais para a análise do AIA, construiu-se a curva analítica. Esta foi preparada a partir de um padrão da marca Supelco na concentração de $100 \mathrm{mg} \mathrm{L}^{-1}$ com cinco pontos, em que cada ponto foi feito em triplicada, com as respectivas concentrações 0,$5 ; 1,0 ; 2,5 ; 5,0$ e $10 \mathrm{mg} \mathrm{L}^{-1}$. Todos os pontos da curva analítica foram preparados utilizando-se o solvente metanol. Essas soluções foram analisadas em ordem crescente de concentração.

\subsection{Limite de deteç̧ão}

Para a determinação do limite de detecção do método foram preparadas soluções de AIA nas seguintes concentrações: 0,$05 ; 0,1 ; 0,25 \mathrm{mg} \mathrm{L}^{-1} \mathrm{em}$ metanol.

\subsection{Ensaio de precisão}

Para a determinação da precisão, cada ponto foi feito em quintuplicata em três níveis de concentração: 0,$75 ; 2,0$ e $8 \mathrm{mg} \mathrm{L}^{-1}$. Essas concentrações foram empregadas por estarem na faixa linear utilizada, porém as concentrações foram diferentes das utilizadas na curva analítica Todas as soluções foram analisadas por HPLC nas condições descritas no item condições cromatográficas para a determinação do AIA em água.

\subsection{Ensaio de recuperação}

Uma amostra de água natural, coletada na nascente do rio Santa Maria do Leme, no município de São Carlos - SP, foi fortificada com a solução padrão do AIA para preparar duas soluções de concentrações 1,0 e $100 \mu \mathrm{g} \mathrm{L}^{-1} \mathrm{e}$, as soluções foram acidificadas com $2 \%$ de ácido fórmico $(\mathrm{v} / \mathrm{v})$. Foram feitas cinco repetições para cada concentração, e também se fez um branco. As amostras foram então pré-concentradas, utilizando-se o método de extração em fase sólida (SPE). Os cartuchos utilizados foram do tipo ODS-C18, os quais foram ativados 
com $10 \mathrm{~mL}$ de metanol acidificado com $1 \%$ de ácido fórmico (v/v), seguido de $10 \mathrm{~mL}$ de água livre de orgânicos. Transferiram-se as amostras para os cartuchos a uma vazão de aproximadamente $1 \mathrm{~mL} / \mathrm{min}^{-1}$. Secou-se o adsorvente contendo o analito no vácuo por duas horas e eluiu-se com $10 \mathrm{~mL}$ de metanol. As amostras foram secas em corrente de nitrogênio e retomadas com $1 \mathrm{~mL}$ de metanol. Os extratos resultantes foram então analisados em HPLC, empregando-se as mesmas condições descritas no item condições cromatográficas para a determinação do AIA em água. A amostra de concentração de $1,0 \mu \mathrm{g} \mathrm{L}^{-1}$ foi pré-concentrada 250 vezes e a de concentração $100 \mu \mathrm{g} \mathrm{L}^{-1}$ foi pré-concentrada 25 vezes.( estou em dúvida quanto a este símbolo de medida, não sei a que elemento ele se refere, é litro?).

\section{RESULTADOS E DISCUSSÃO}

\subsection{Espectro de UV e cromatograma do padrão do ácido 3- indolacético}

A Figura 1 apresenta o espectro de UV do padrão do AIA, obtido com o intuito de verificar a região de absorção da substância em estudo e o formato do pico. O pico com comprimento de onda de $217 \mathrm{~nm}$ é referente ao grupo ácido carboxílico e o pico em $280 \mathrm{~nm}$ refere-se ao grupo indol. O comprimento de onda correspondente à absorção máxima do analito em estudo, que foi selecionado para a determinação analítica empregando-se um cromatógrafo em fase líquida com detector de UV-Vis, foi de $280 \mathrm{~nm}$.

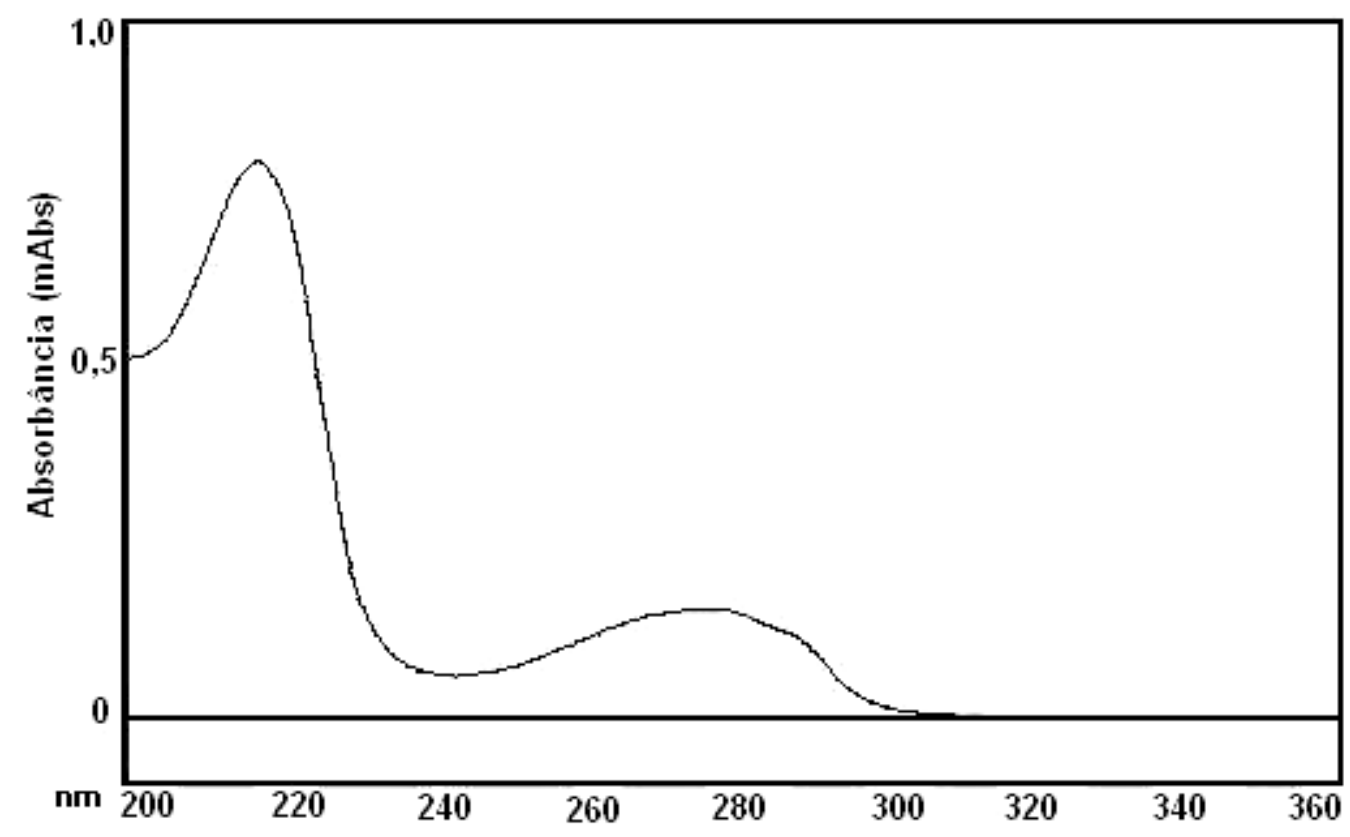

Figura 1. Espectro de UV-Vis do padrão do ácido 3-indolacético.

A Figura 2 apresenta o cromatograma do padrão do AIA na concentração de $100 \mathrm{mg} \mathrm{L}^{-1}$. Utilizou-se a fase móvel metanol/TFA $(0,05 \%)$. (40:60 v/v). 


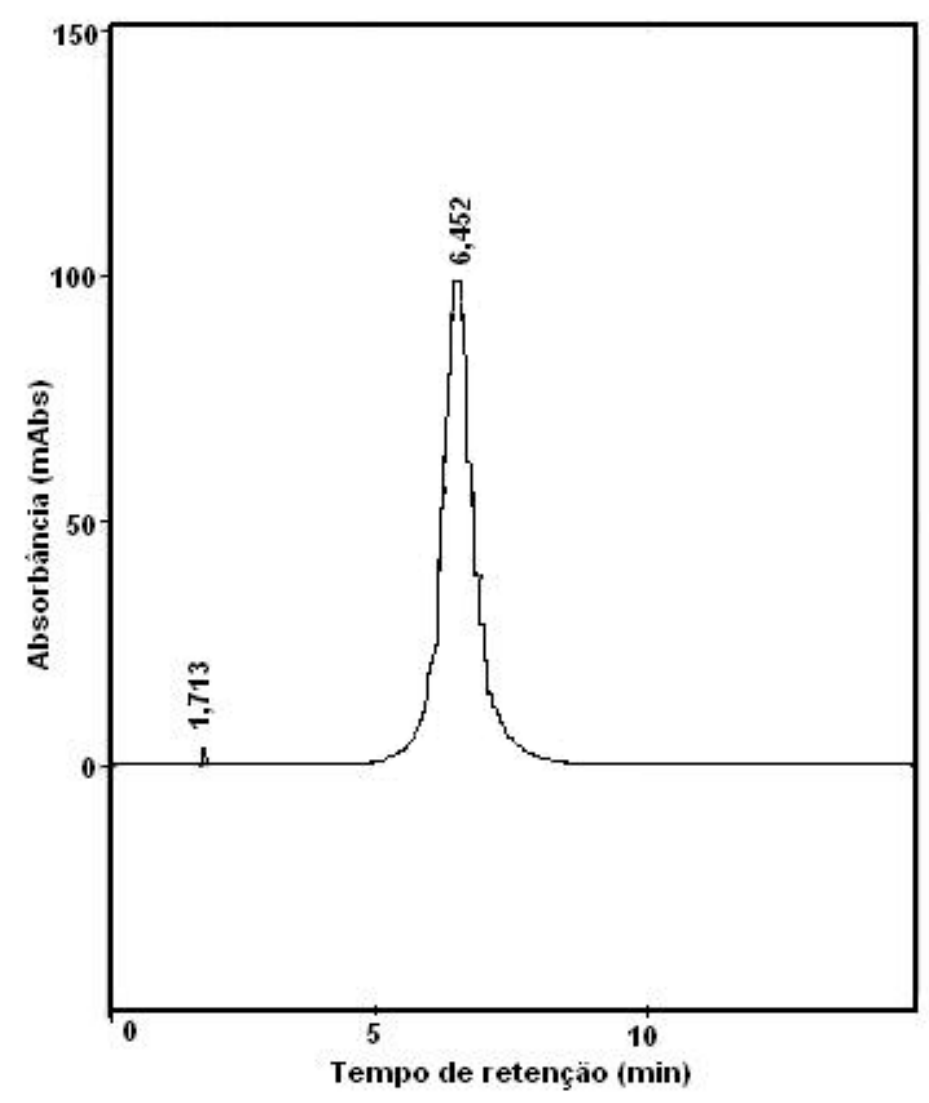

Figura 2. Cromatograma do padrão do ácido 3 indolacético (100 mg L-1).

Verifica-se pelo cromatograma que o pico cromatográfico referente ao AIA está bem definido. Os tempos de retenção do solvente (metanol) e do ácido 3 - indolacético foram, respectivamente, de 1,713 e $6,452 \mathrm{~min}$.

\subsection{Linearidade da curva analítica a ser usada para a determinação do ácido 3 - indolacético em água}

A curva analítica apresentada na Figura 3 foi construída com cinco pontos, em um intervalo de concentração de 0,5 a $10 \mathrm{mg} \mathrm{L}^{-1}$.

A curva analítica obtida para o AIA foi linear, apresentando coeficiente de correlação (R) superior a 0,99. A Agência Nacional de Vigilância Sanitária (Brasil, 2003) recomenda um coeficiente de correlação igual a 0,99 e o Instituto Nacional de Metrologia, Normalização e Qualidade Industrial (Brasil ,2003) acima de 0,90. Esse coeficiente de correlação foi satisfatório, o que demonstra que a resposta do detector foi linear nos intervalos de concentração empregados nesse estudo (Ribani et al., 2004). 
SANCHES, S.M.; MARTINS, R.; CORDEIRO, P.J.M.; VAZ, L.A.A.; VIEIRA, E.M. Validação do método para a determinação do ácido 3 - indolacético em água de rios por cromatografia líquida de alta eficiência. Ambi-Agua, Taubaté, v. 4, n. 1, p. 81-92, 2009. (doi:10.4136/ambi-agua.75)

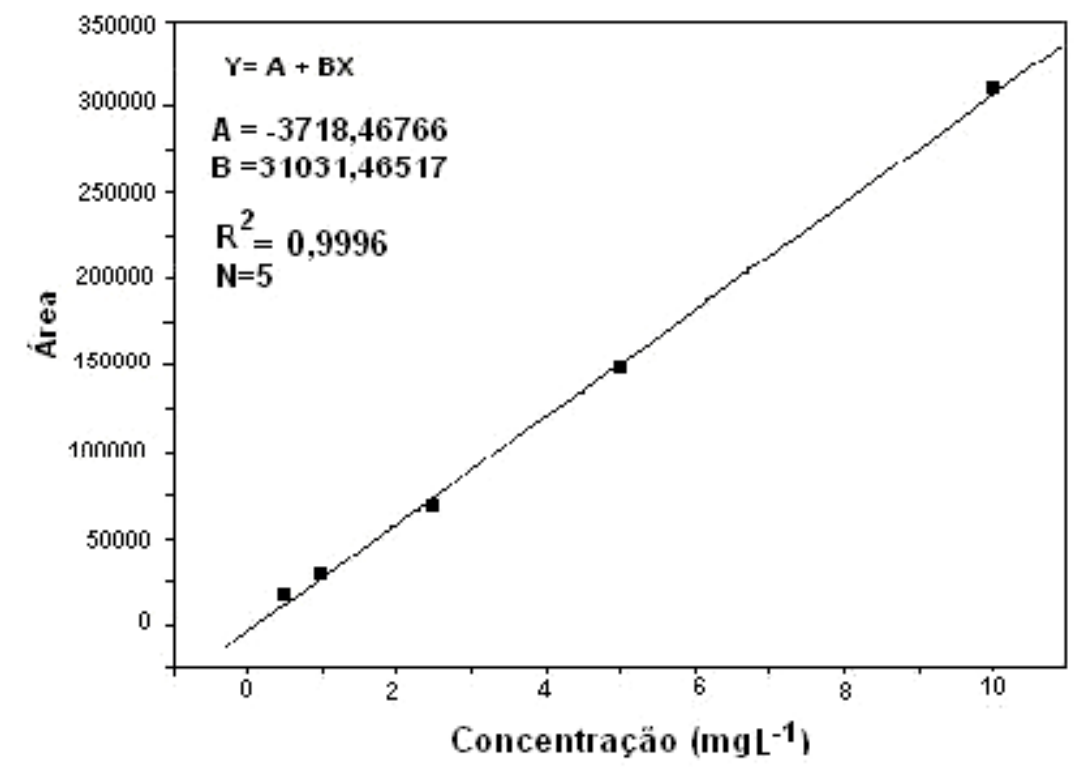

Figura 3. Curva analítica do ácido 3 - indolacético.

\subsection{Limites de deteç̧ão e de quantificação}

Nas Figuras 4 e 5, apresentam-se, respectivamente, os cromatogramas, evidenciando o limite de detecção do método, e também a região do pico expandida para verificar a relação entre a altura do pico e a altura do ruído da linha de base.

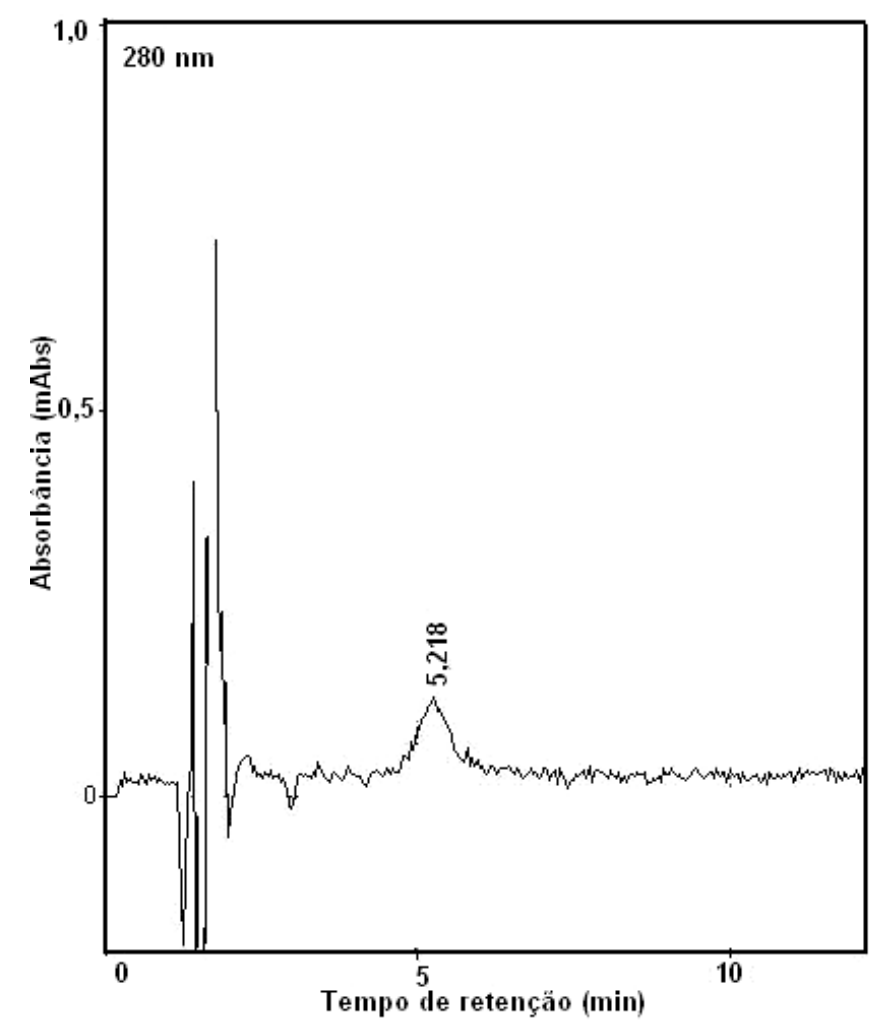

Figura 4. Cromatograma do limite de detecção do método. 


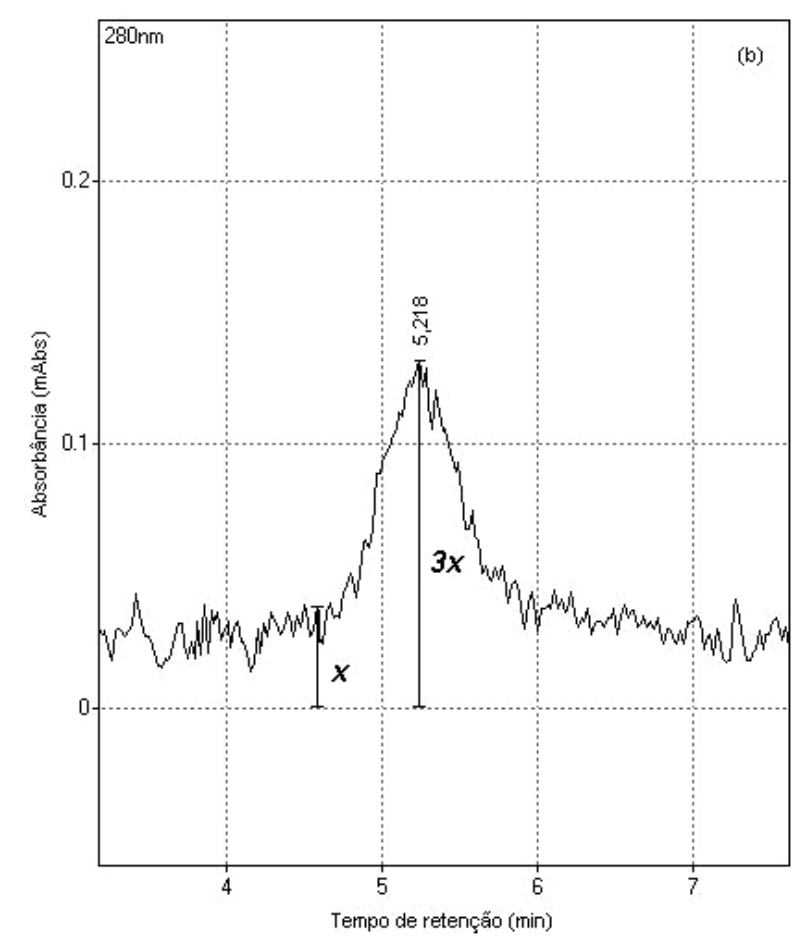

Figura 5. Cromatograma do limite de deteç̧ão do método, região do pico aumentada.

O limite de detecção do método foi de $0,05 \mathrm{mg} \mathrm{L}^{-1}$, cuja estimativa foi feita com base na relação: a altura do pico do analito deve ser em torno de 3 vezes a altura do ruído da linha de base, na região aproximada do tempo de retenção do AIA. Já o limite de quantificação é dado pela equação $\mathrm{LQ}=10 \mathrm{x}(\mathrm{s} / \mathrm{S})$, em que: $\mathrm{s}=$ desvio-padrão da resposta e $\mathrm{S}=$ coeficiente angular do gráfico de calibração. O limite de quantificação foi de $0,5 \mathrm{mg} \mathrm{L}^{-1}$.

\subsection{Sensibilidade da técnica analítica para a determinação do AIA}

Da equação da reta pode-se estimar a sensibilidade da técnica que é definida como dy/dx, a qual foi de 31031,46517, que é considerado como de sensibilidade alta (Ribani et al., 2004).

\subsection{Ensaio de precisão}

Segundo regulamentação da (Brasil, 2003), a precisão pode ser calculada por meio do coeficiente de variação pela equação:

$$
C V=\frac{D P}{C M D} \times 100
$$

em que, DP é o desvio padrão e CMD, a concentração média determinada.

O valor máximo aceitável deve ser definido de acordo com a metodologia empregada, com a concentração do analito na amostra, com o tipo de matriz e com a finalidade do método, não se admitindo valores superiores a 5\%. A estimativa do desvio padrão pode ser calculada pela equação:

$$
D P=\sqrt{\frac{\sum\left(X_{i}-\bar{X}\right)^{2}}{N-1}}
$$


em que $\mathrm{X}_{\mathrm{i}}$ é a concentração obtida por meio da análise cromatográfica, $\bar{X}$ é a média e N é o número de medidas.

Neste estudo, a precisão do método foi avaliada referente ao nível de repetibilidade. A repetibilidade apresenta a concordância entre os resultados de medidas sucessivas de um mesmo método, efetuadas sob as mesmas condições que são chamadas condições de repetibilidade: mesmo procedimento; mesmo analista; mesmo instrumento usado sob as mesmas condições; mesmo local; repetições em curto intervalo de tempo (Ribani et al., 2004). A precisão foi avaliada por meio do coeficiente de variação (CV) dos resultados obtidos $(\mathrm{n}=5)$, ao nível de repetibilidade, sendo portanto feita em um curto intervalo de tempo. $\mathrm{Na}$ Tabela 1, encontram-se os resultados da precisão do método usado neste estudo.

Tabela 1. Dados obtidos para o ensaio de precisão.

\begin{tabular}{|c|c|c|c|c|}
\hline $\begin{array}{l}\text { Concentração } \\
\left(\mathrm{mg} \mathrm{L}^{-1}\right)\end{array}$ & $\begin{array}{c}\text { Concentração obtida } \\
\left(\mathrm{mg} \mathrm{L}^{-1}\right)\end{array}$ & Média & Desvio padrão & CV (\%) \\
\hline 0,75 & $\begin{array}{l}0,7532 \\
0,7683 \\
0,7706 \\
0,7741 \\
0,7835\end{array}$ & 0,7699 & 0,01 & 1,3 \\
\hline 2,0 & $\begin{array}{l}2,1403 \\
2,1307 \\
2,0598 \\
2,1253 \\
2,0951\end{array}$ & 2,1102 & 0,03 & 1,5 \\
\hline 8,0 & $\begin{array}{l}8,1521 \\
8,2932 \\
8,1147 \\
8,1345 \\
8,2369\end{array}$ & 8,1863 & 0,07 & 0,9 \\
\hline
\end{tabular}

Como pode ser observado na Tabela 1 , os coeficientes de variação variaram de 0,9 a 1,5 $\%$, sendo esses valores menores do que os estipulados pela Agência Nacional de Vigilância Sanitária que é de $5 \%$, sendo portanto, o método considerado preciso e dentro da faixa aceitável para a validação de métodos analíticos (Ribani et al., 2004).

\subsection{Ensaios de recuperação}

Optou-se por acidificar a amostra com $2 \%$ de ácido fórmico, podendo-se obter uma melhor recuperação do analito estudado. A Tabela 2 apresenta a porcentagem de recuperação do AIA em água para os dois níveis de fortificação estudados 0,1 e $0,001 \mathrm{mg} \mathrm{L}^{-1}$. Os ensaios de recuperação foram feitos em quintuplicata.

Tabela 2. Porcentagens de recuperação do ácido 3-indolacético em água.

\begin{tabular}{c|c|c}
\hline Nível de fortificação $\left(\mathbf{m g ~ L}^{-\mathbf{1}}\right)$ & Recuperação (\%) & CV (\%) \\
\hline 0,1 & $120(113-127)$ & 4,9 \\
0,001 & $80(74-82)$ & 4,8 \\
\hline
\end{tabular}


Analisando-se os dados contidos na Tabela 2, observa-se que houve uma boa recuperação, o que indica que o método empregado é apropriado para a análise de AIA em água, pois o valor está dentro dos limites aceitáveis de recuperação que é de 70 a $120 \%$ (ICH, 1995).

As porcentagens de recuperação obtidas deixam evidente que o método pode ser considerado preciso. A precisão foi avaliada por meio do coeficiente de variação $(\mathrm{CV})$ dos resultados obtidos ( $\mathrm{N}=5)$, cujos valores são inferiores a $5 \%$ para este método.

Nas Figuras 5 e 6 encontram-se apresentados os cromatogramas obtidos para o ensaio de recuperação do AIA em água, nos níveis de fortificação estudados, 0,1 e 1,0 $\mathrm{mg} \mathrm{L}^{-1}$.

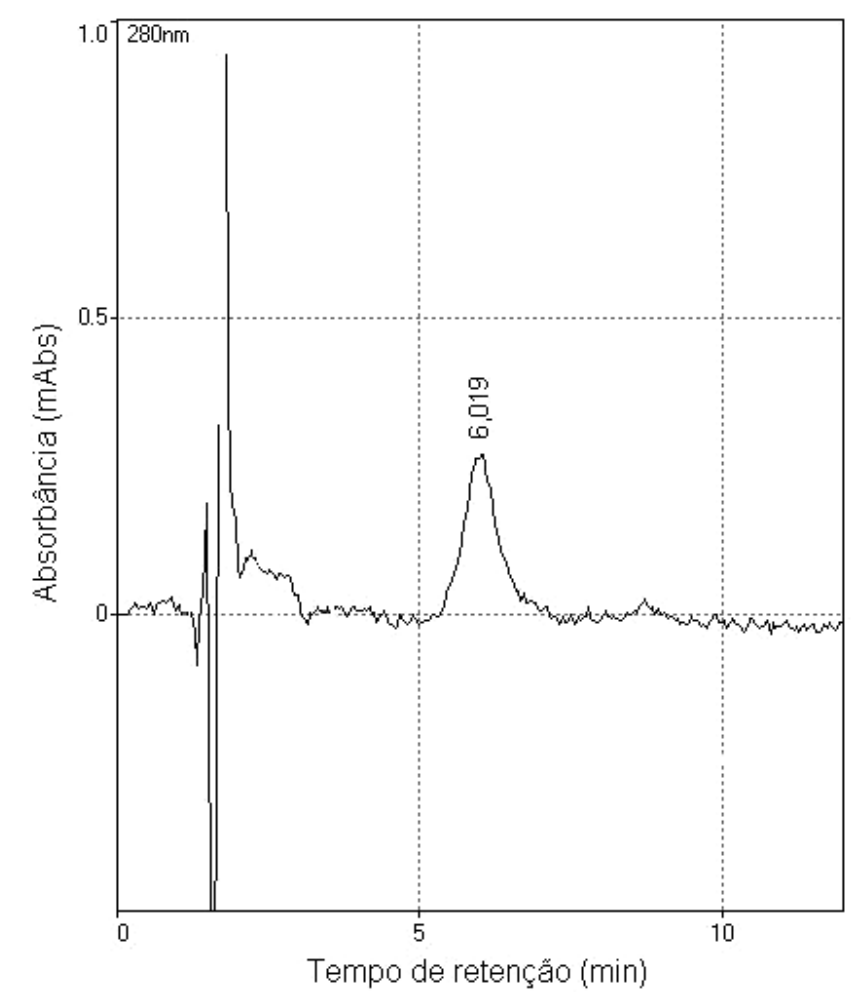

Figura 5. Cromatograma obtido para o ensaio de recuperação do AIA em água no nível de fortificação $0,1 \mathrm{mg} \mathrm{L}^{-1}$.

As amostras fortificadas com AIA foram pré-concentradas 2,5 vezes e as áreas dos picos obtidos foram de 10781 para $0,1 \mathrm{mg} \mathrm{L}^{-1}$ e de 73415 para $1,0 \mathrm{mg} \mathrm{L}^{-1}$. Na Figura 7, está apresentado o cromatograma obtido para o branco. Como pode ser observado, o pico referente ao AIA (tempo de retenção de aproximadamente $6 \mathrm{~min}$ ) não está presente, indicando a ausência desse fitormônio na água coletada na nascente do rio Santa Maria do Leme. A amostra de água foi pré-concentrada 250 vezes, para se garantir que o ácido 3 - indolacético não estaria presente. 
SANCHES, S.M.; MARTINS, R.; CORDEIRO, P.J.M.; VAZ, L.A.A.; VIEIRA, E.M. Validação do método para a determinação do ácido 3 - indolacético em água de rios por cromatografia líquida de alta eficiência. Ambi-Agua, Taubaté, v. 4, n. 1, p. 81-92, 2009. (doi:10.4136/ambi-agua.75)

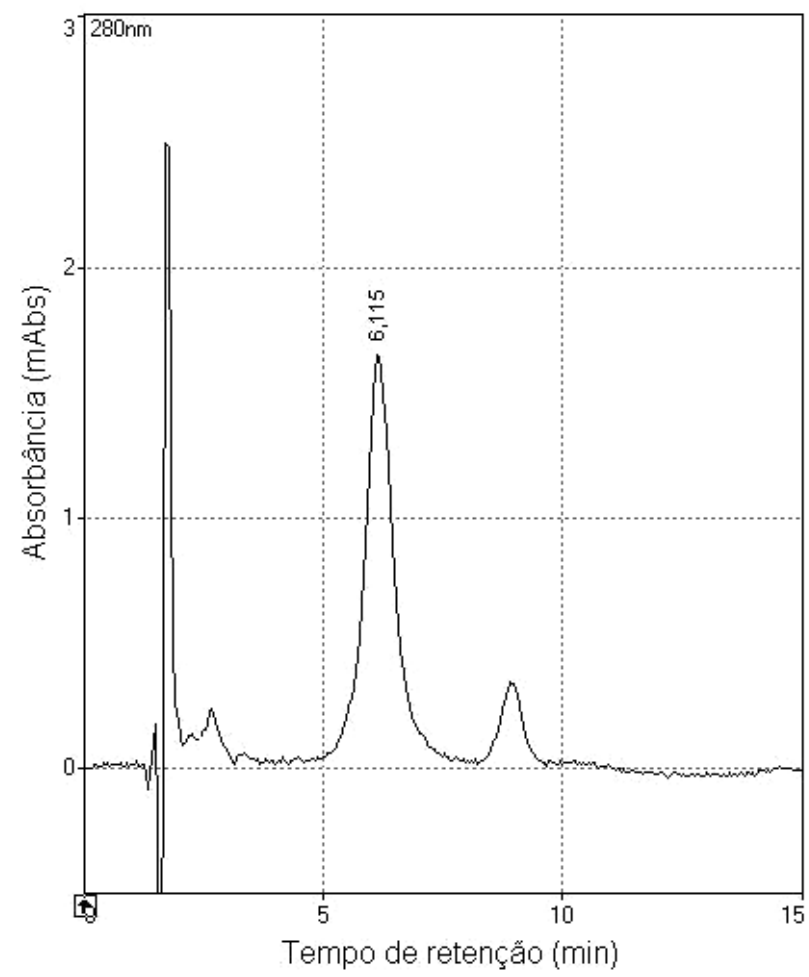

Figura 6. Cromatograma obtido para o ensaio de recuperação do AIA em água no nível de fortificação $1 \mathrm{mg} \mathrm{L}^{-1}$.

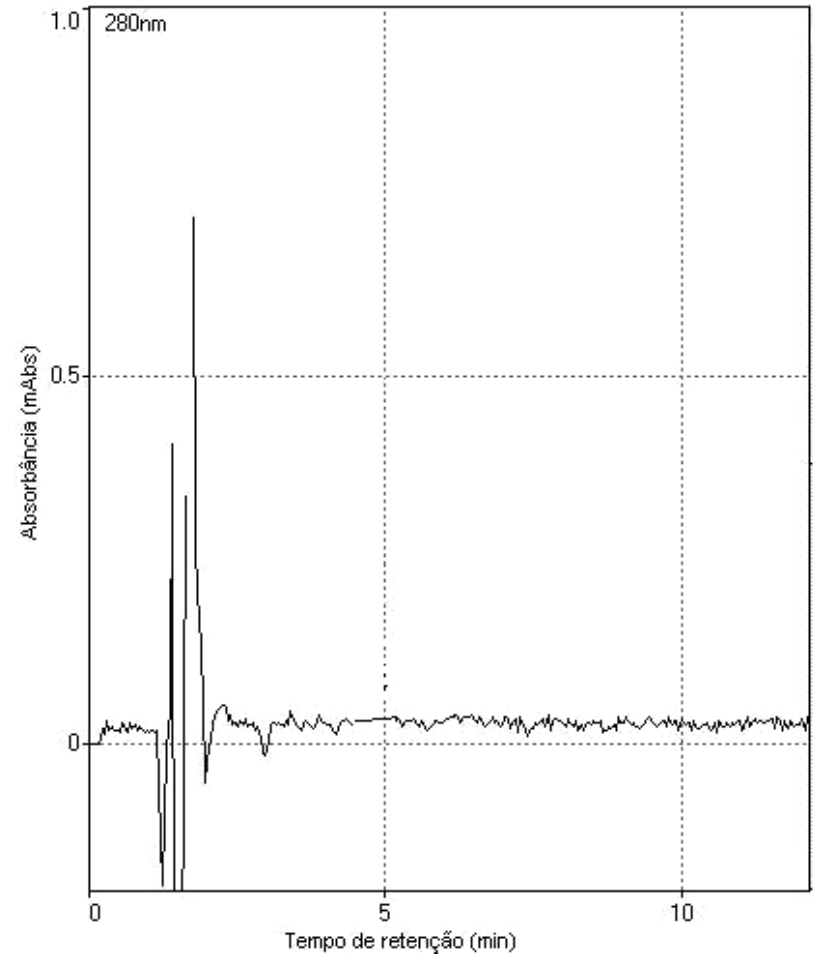

Figura 7. Cromatograma do branco. 


\section{CONCLUSÃO}

Atualmente vem crescendo a preocupação com respeito à poluição, sobretudo à da água. Como as práticas agrícolas contribuem para a poluição da água é, portanto, necessário o desenvolvimento e validação de métodos para a determinação do ácido 3 - indolacético, o qual é um fitormônio amplamente utilizado na agricultura. $\mathrm{O}$ método desenvolvido mostrouse eficiente para tal determinação, estando de acordo com as normas estabelecidas pelos órgãos fiscalizadores, ANVISA, INMETRO e ICH. Vale ressaltar que durante o desenvolvimento e validação de um método, os procedimentos analíticos devem ser submetidos à validação estatística, com o objetivo de conhecer suas limitações e confiabilidade dos resultados obtidos, para a aplicação do método para amostras que se deseja analisar.

\section{AGRADECIMENTOS}

À Fundação de Amparo à pesquisa do Estado de São Paulo - FAPESP, pela apoio concedido para a execução deste trabalho.

\section{REFERÊNCIAS}

ALVARENGA, L. R.; CARVALHO, V. D. Uso de substâncias promotoras de enraizamento de estacas frutíferas. Informe Agropecuário, Belo Horizonte, v. 9, n.101, p. 47-55, 1983.

ARTECA, R. N. Plant Growth Substances: principles and application. New York: Chapman and Hall, 1995. 332p.

BRASIL. Ministério da Saúde. Agência Nacional de Vigilância Sanitária - ANVISA. Resolução RE n. 899 de 29 de maio de 2003. Disponível em: $<$ http://www.anvisa.gov.br/legis/resol/2003/re/899_03re.htm>. Acesso em: 20 de Dezembro de 2008.

BRASIL. Ministério da Saúde. Secretaria de Vigilância em Saúde. Coordenação-Geral de Vigilância em Saúde Ambiental. Portaria n 518/2004, de 25 de Março de 2004: estabelece os procedimentos e responsabilidades relativas ao controle de vigilância da qualidade da água para o consumo humano e seu padrão de potabilidade, e dá outras providências. Disponível em: <http://portal.saude.gov.br/portal/arquivos/pdf/portaria _518_2004.pdf >. Acesso em: 30 de Dezembro de 2008.

CASTRO, P. R. C.; APPEZZATO-DA-GLÓRIA, B. Efeitos de reguladores vegetais no desenvolvimento e na produtividade do amendoinzeiro (Arachis hypogaea L.), Scientia Agrícola, Piracicaba, v. 50, n. 2, p. 176 - 184, 1993.

INSTITUTO NACIONAL DE METROLOGIA, NORMALIZAÇÃO E QUALIDADE INDUSTRIAL -INMETRO. Orientações sobre validação de métodos de ensaios, DOQ-CGCRE-008. Disponível em: <http://www.inmetro.gov.br/Sidoq/ Arquivos/CGCRE/DOQ/DOQ-CGCRE-8_02.pdf>. Acesso em: 10 de Janeiro de 2009.

Internacional Conference on Harmonization - ICH, Q2A: validation of analytical procedures: definitions and terminology, Q2A (CPMP/ICH/381/95), 1995. Disponível em: $<$ http://www.tga.gov.au/meds/eucons/ich038195enrrev1.pdf $>$. Acesso em: 15 de Dezembro de 2008. 
RIBANI, M.; BOTTOLI, C. B. G.; COLLINS, C. H. \& JARDIM, I. C. S. F. Validação em métodos cromatográficos e eletroforéticos. Química Nova, v. 27, n. 5, p. $771-780,2004$.

ROLCIK, J.; RECINSKA, J.; BARTAK, P.; STRNAD. M.; PRINSEN, E. Purification of 3indolylacetic acid by solid phase extraction. Journal of Separation Science, v. 28, p. 1370-1374, 2005.

WACHOWICZ, C. M.; CARVALHO, R. I. N. Fisiologia Vegetal: produção e pós-colheita. Curitiba: Editora Universitária Champagnat, 2002, 424p.

WURST, M.; PRIKRYL, Z.; VOKOUN, J. High-performance liquid chromatography of plants hormones: II. Determination of plant hormones of the indole type. In: Journal of Chromatography, v. 286, p.237-245, 1984. 